\title{
R116C Mutation of Cationic Trypsinogen in a Turkish Family with Recurrent Pancreatitis Illustrates Genetic Microheterogeneity of Hereditary Pancreatitis
}

\author{
G. Tautermann $^{a} \quad H$. Ruebsamen $^{b} \quad M$. Beck $^{b} \quad$ S. Dertinger ${ }^{a} \quad H$. Drexel $^{a}$ \\ P. Lohse ${ }^{b}$ \\ ${ }^{a}$ Department of Internal Medicine, Landeskrankenhaus Feldkirch, Austria; bepartment of Clinical Chemistry- \\ Grosshadern, University Hospital, University of Munich, Germany
}

\section{Key Words}

Pancreas - Chronic pancreatic disease .

Pathophysiology, pancreatic disease - Zymogen

inactivation - Autosomal dominant genetic disorder •

Gain-of-function mutation

\begin{abstract}
Hereditary pancreatitis is due to heterozygosity for gainof-function mutations in the cationic trypsinogen gene which result in increased levels of active trypsin within pancreatic acinar cells and autodigestion of the pancreas. The number of disease-causing defects is generally considered to be low. To gain further insight into the molecular basis of this disorder, DNA sequence analysis of all five exons was performed in 109 unrelated patients with idiopathic chronic pancreatitis in order to determine the variability of the underlying mutations. Two German females and one German male were carriers of the most common N29I and R122H mutations (trypsinogen numbering system). In a Turkish proband, an arginine (CGT) to cysteine (TGT) substitution at amino acid position 116 was identified. Family screening demonstrated that the patient had inherited the mutation from his asymptomatic father and that he had transmitted it to both of his children, his daughter being symptomatic since the age of 3
\end{abstract}

\begin{tabular}{ll}
\hline KARGER & ( 2002 S. Karger AG, Basel \\
Fax +41612-2823/01/0644-0226\$17.50/0 \\
$\begin{array}{l}\text { E-Mail karger@ } 1234 \\
\text { www.karger.ch }\end{array}$ & $\begin{array}{l}\text { Accessible online at: } \\
\text { www.karger.com/journals/dig }\end{array}$
\end{tabular}

years. In addition, a German male was found to be a heterozygote for a $\mathrm{D} 100 \mathrm{H}$ (GAC $\rightarrow \mathrm{CAC}$ ) amino acid replacement. Our data provide evidence for genetic heterogeneity of hereditary pancreatitis. The growing number of cationic trypsinogen mutations is expected to change current mutation screening practices for this disease.

Copyright @ 2002 S. Karger AG, Basel

\section{Introduction}

Hereditary pancreatitis is a rare autosomal dominant disorder with about $80 \%$ penetrance and variable expressivity [for a review see 1-4]. Onset of disease occurs at a mean age of $14.1 \pm 11.9$ years [5]. In comparison with alcoholic pancreatitis, patients suffering from hereditary pancreatitis are less likely to develop pancreatic calcifications or diabetes. They also have a lower overall mortality rate. The risk of pancreatic cancer, however, is increased, especially if the disease is inherited through the paternal side of the family, and smoking appears to be an important additional risk factor [5].

Since the first report of hereditary pancreatitis in 1952 [6], more than 150 kindreds have been identified worldwide, the majority of which are of Caucasian ancestry with a few families reported from Japan [7-13].

Dr. Peter Lohse

Department of Clinical Chemistry - Grosshadern, University Hospital

Marchioninistrasse 15

D-81377 Munich (Germany)

Tel. +49 897095 3233, Fax +49 897095 8888, E-Mail lohse@klch.med.uni-muenchen.de 
In 1996, advances in molecular genetics enabled two independent groups to map the hereditary pancreatitis locus to chromosome $7 \mathrm{q} 35[14,15]$, partially overlapping the $\mathrm{T}$ cell receptor beta locus [16]. Of the eight genes found in this locus, only two appear to be functional and to code for cationic and anionic trypsinogen [16-18]. In the same year, the first disease-specific mutation $(\mathrm{R} 122 \mathrm{H}$; numbering according to the trypsinogen nomenclature, corresponding to chy\#R117H) was identified in the cationic trypsinogen gene by Whitcomb et al. [9]. This was followed by the report of a second common disease-specific mutation (N29I, corresponding to chy\#N21I) in 1997 [19]. The genetic heterogeneity of hereditary pancreatitis has been illustrated by the discovery of additional mutations in exon 1 (TCC deletion at positions -28 to -30 with respect to the ATG start codon) [11], exon 2 (A16V, D22G, K23R, and P36R), and exon 3 (E79K, G83E, K92N, and V123M) [11, 20-22]. In addition, the sequences of three allelic variants (L104P, R116C, and C139F) have been deposited in the Genbank of the National Center for Biotechnology Information, National Library of Medicine, National Institutes of Health, by Teich and coworkers in November 2000 (accession Nos. AF315309-AF315311).

To determine the frequency of hereditary pancreatitis and the heterogeneity of the underlying mutations, we studied 109 unrelated Caucasian probands with idiopathic chronic pancreatitis. Besides the common N29I and $\mathrm{R} 122 \mathrm{H}$ mutations, two additional amino acid substitutions were identified in this group of patients: a D100H substitution in a German male with idiopathic chronic pancreatitis and an $\mathrm{R} 116 \mathrm{C}$ mutation in 4 members of a Turkish family, 2 of them being symptomatic carriers.

\section{Subjects and Methods}

\section{Ethical Considerations}

Written informed consent was obtained from all participants, and the research was carried out in accordance with the ethical guidelines of the 1975 Declaration of Helsinki.

\section{DNA Isolation and Amplification by PCR}

Genomic DNA was extracted from white blood cells using the QIAGEN (Hilden, Germany) blood minikit and amplified by PCR with nested primer pairs which flank the five coding exons of the cationic trypsinogen gene. Each $50-\mu 1$ reaction mixture of the first round of amplification contained $20 \mu M$ of each oligonucleotide primer, $200 \mu M$ of each dNTP, approximately $300 \mathrm{ng}$ of highmolecular-weight DNA, and 1.25 U HotStarTaq DNA polymerase (QIAGEN) in a Tris/ $\mathrm{KCl} /\left(\mathrm{NH}_{4}\right)_{2} \mathrm{SO}_{4}$ buffer (pH 8.7) with $1.5 \mathrm{mM}$ $\mathrm{MgCl}_{2}$ and $1 \times \mathrm{Q}$ solution. After denaturation at $95^{\circ} \mathrm{C}$ for $15 \mathrm{~min}$, DNA was amplified for 25 cycles at $95^{\circ} \mathrm{C}$ for $20 \mathrm{~s}$, at $53^{\circ} \mathrm{C}$ (exon 5), $56^{\circ} \mathrm{C}$ (exons 1 and 2 ), $58^{\circ} \mathrm{C}$ (exon 4), or $61^{\circ} \mathrm{C}$ (exon 3) for $20 \mathrm{~s}$, and at $72^{\circ} \mathrm{C}$ for $30 \mathrm{~s}$. The second, nested PCR reaction was performed with $5 \mu \mathrm{l}$ of the first PCR mixture under identical conditions, except for the primers. The amplification profile included denaturation at $95^{\circ} \mathrm{C}$ for $20 \mathrm{~s}$, primer annealing at $61^{\circ} \mathrm{C}$ (exon 3$), 63^{\circ} \mathrm{C}$ (exons 1 and 2), $64^{\circ} \mathrm{C}$ (exon 5), or $65^{\circ} \mathrm{C}$ (exon 4) for $20 \mathrm{~s}$, and elongation at $72^{\circ} \mathrm{C}$ for $30 \mathrm{~s}$ for a total of 40 cycles.

\section{DNA Sequence Analysis}

Amplification products were isolated using the QIAquick PCR purification kit (QIAGEN). Cycle sequencing was performed with the nested primer set, 3'-dye-labeled dideoxynucleotide triphosphates (dye terminators), and AmpliTaq DNA polymerase on an Applied Biosystems (Foster City, Calif., USA) 377 DNA sequencer. Mutations were confirmed by second-strand sequencing.

Restriction Fragment Length Polymorphism Analysis

Ten units of restriction endonuclease Bbr PI (Pma CI; 5'-CAC/ GTG-3'; Roche Diagnostics, Mannheim, Germany) was used for mutation detection, as the $\operatorname{Arg}_{116}$ (CGT) $\rightarrow$ Cys (TGT) substitution results in the loss of the only Bbr PI site within the amplified exon 3 fragment (PC/GENE; IntelliGenetics, Mountain View, Calif., USA). After overnight incubation, restriction digests were loaded on 2\% low melting point agarose gels (Gibco BRL Life Technologies, Rockville, Md., USA), and the DNA fragments were visualized by ethidium bromide staining and ultraviolet transillumination.

\section{Results}

In an attempt to identify patients with hereditary pancreatitis and to determine the heterogeneity of the underlying mutations, we have sequenced the coding exons of the cationic trypsinogen gene in 109 Caucasian patients with the diagnosis of idiopathic chronic pancreatitis.

One female $(* 1975)$ was a heterozygous carrier of the N29I substitution, and in another female $(* 1952)$ and in a male proband $(* 1965)$, the $\mathrm{R} 122 \mathrm{H}$ mutation was present. In addition, 1 male patient $(* 1960)$ was found to be a heterozygote for an aspartic acid (GAC) to histidine (CAC) replacement at amino acid position 100 of cationic trypsinogen $(\mathrm{D} 100 \mathrm{H}$; fig. 1). The causal relationship between this mutation and the chronic pancreatitis present in this subject could not be proven, because the proband did not give his consent to further family studies. Comparison with the amino acid sequences of anionic trypsinogen, mesotrypsinogen, and chymotrypsinogen demonstrated that the aspartic acid at position 100 is not strictly conserved, being replaced by asparagine in anionic trypsinogen and mesotrypsinogen and by isoleucine in chymotrypsinogen. The $\mathrm{D} 100 \mathrm{H}$ substitution could, therefore, be a rare polymorphism not observed in the other 108 unrelated subjects studied thus far. However, the suspicion that this variant may be of pathogenetic relevance is sup- 
ported by the identification of a leucine-to-proline replacement at amino acid position 104 (L104P; Genbank accession No. AF315309) in members of a German family suffering from chronic pancreatitis, strongly suggesting that alterations in this particular region of the molecule are associated with a genetic predisposition to chronic pancreatitis.

We also identified 2 subjects, an Italian male $(* 1964)$ and a Turkish female $(* 1990)$, who were heterozygotes for previously also not reported $\mathrm{G} \rightarrow$ A mutations at positions -79 and -78 with respect to the intron $4 /$ exon 5 border. Whether these nucleotide substitutions, which occur within a stretch of four guanines in intron 4 , are of any functional significance remains to be determined.

A fourth amino acid substitution, an arginine-to-cysteine exchange at position 116 of cationic trypsinogen (present in Genbank as TRYP1-R116C allele; accession No. AF315310), was detected in a Turkish family with 2 members being affected by chronic pancreatitis and is presented in detail below.

Thirty-four probands were heterozygotes for the already described intragenic polymorphisms $[10-12,19]$ in exon $4(\mathrm{GAC} \rightarrow$ GAT; D162D) and in exon 5 (AAC $\rightarrow$ AAT; N246N) which, in our experience, are tightly linked in cis and, therefore, appear to be located on the same allele. Twenty-six subjects were homozygotes for these two silent mutations, and 44 patients had inherited the wild-type sequence on both of their alleles. In 5 cases, only exons $1-3$ were analyzed.

\section{Family Characteristics}

The 28-year-old Turkish male R.D. was admitted to the Department of Internal Medicine of the Landeskrankenhaus Feldkirch, Austria, in February 2000 with a 1year history of recurrent upper abdominal pain and a weight loss of $9 \mathrm{~kg}$. The patient had no past history of illness or alcohol abuse, and he was not taking regular medications.

On examination, he had spontaneous and palpatory evoked pain in the right upper abdomen. The leukocyte count was $9.8 \times 10^{9} / 1$, liver transaminases were in the high-normal range (AST $19 \mathrm{U} / 1$, ALT $28 \mathrm{U} / 1$ ), and the $\gamma$ glutamyltransferase concentration was increased threefold $(83 \mathrm{U} / 1)$, while the lipase and alkaline phosphatase levels were normal.

Imaging diagnostics (abdominal X-ray, CT scan) demonstrated pancreatic calcifications in head and body. ERCP verified the pancreatic duct irregularities and a single pancreatic duct stone in the head first detected by ultrasonography. Due to papillary stenosis, a papillotomy was carried out, and a 10-Fr stent was implanted into the pancreatic duct. A minor secondary stenosis of the bile duct was also treated with papillotomy, as a result of which normal liver enzyme values were obtained. Liver disease had initially been ruled out serologically and through biopsy.

The patient has 2 children, his daughter R.D. (*1993) being symptomatic twice a year since the age of 3 years with upper abdominal pain radiating to the back. Transabdominal ultrasound and magnetic resonance cholangiopancreatography, performed in May 2001, did not show any complications associated with chronic pancreatitis (e.g., ductal irregularities and dilatation, calcifications, pseudocysts). Exocrine function tests, done at the same time, revealed no signs of pancreatic dysfunction.

Knowledge of additional family members with recurrent attacks of abdominal pain or symptoms typical of diabetes mellitus was negated by the proband.

\section{Genetic Analyses}

DNA cycle sequencing of exons $1-5$ of the proband's cationic trypsinogen gene revealed a single $\mathrm{C} \rightarrow \mathrm{T}$ substitution at nucleotide position 146 of exon 3 (numbering relative to the intron 2 /exon 3 border), for which the patient was heterozygous. This mutation results in the replacement of arginine (CGT), residue 116 of cationic trypsinogen, by cysteine (TGT; fig. 2). After identification of the putative mutation, further molecular genetic analyses were carried out in the proband's immediate relatives: his mother Z.D. (*1947), his father M.D. $(* 1946)$, his daughter R.D. $\left({ }^{*} 1993\right)$, and his son E.D. $\left({ }^{*} 1996\right)$. Other family members were not available for testing. DNA sequence analysis demonstrated that, except for the mother, all subjects studied were heterozygotes for the R116C substitution. These results were confirmed by restriction fragment length polymorphism analysis, as softwareassisted screening for polymorphic restriction enzyme sites demonstrated loss of a Bbr PI (Pma CI) site (5'-CAC/ GTG- $3^{\prime}$ ) as a consequence of the $\mathrm{C} \rightarrow \mathrm{T}$ base exchange. Agarose gel electrophoresis of Bbr-PI-digested exon $3 \mathrm{am}-$ plification products also identified the proband, his father, and his 2 children as heterozygous carriers of the mutation by the presence of three instead of two fragments, while the mother served as normal control (fig. 3). 


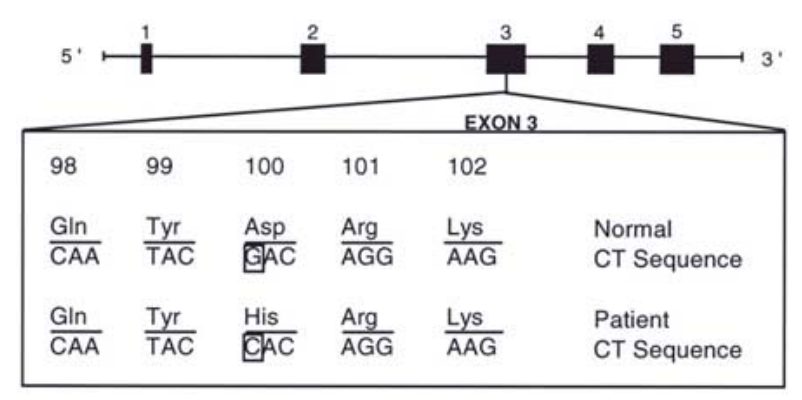

C C C A A T A C G A C A G G A A G

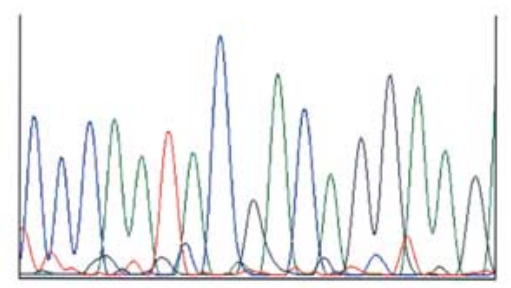

C C C A A T A CNACA G G A G

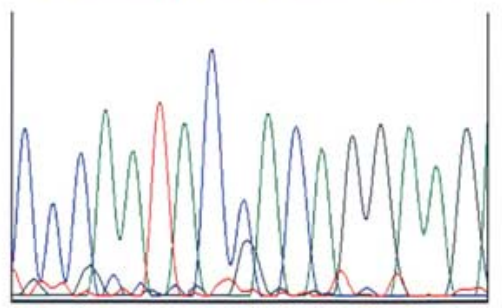

Fig. 1. Sequence analysis of exon 3 of the cationic trypsinogen gene in a control subject and in proband K.W. The five exons of the cationic trypsinogen gene (black boxes) and the intervening intron sequences (lines) as well as the $\mathrm{G} \rightarrow \mathrm{C}$ mutation (boxed) in exon 3, which results in the substitution of aspartic acid (GAC), residue 100, by histidine (CAC), are shown in the upper panel. The lower panel depicts the results of the DNA sequence analysis of exon 3 PCR products from a control (upper part) and from the heterozygous carrier K.W. (lower part).

\section{Discussion}

Hereditary pancreatitis is indistinguishable from other forms of chronic pancreatitis in terms of clinical, laboratory, radiological, and histopathological features. Suspicion is raised in case a subject presents with recurrent episodes of pancreatitis, beginning in childhood or adoles-

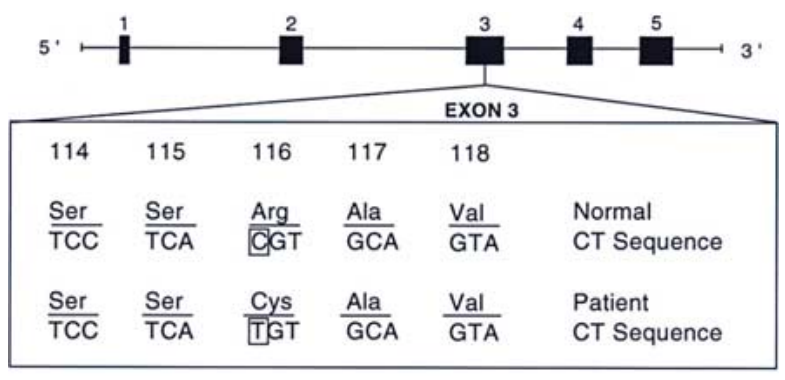

TC T C C T C A C G T G C A G T A

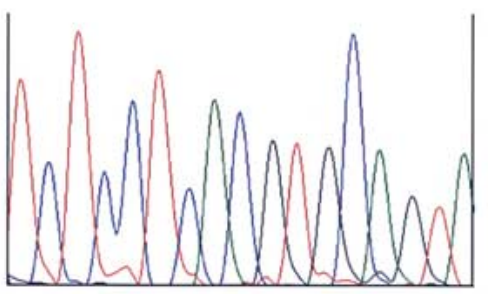

TC T C C T C ANG T G C A G T A

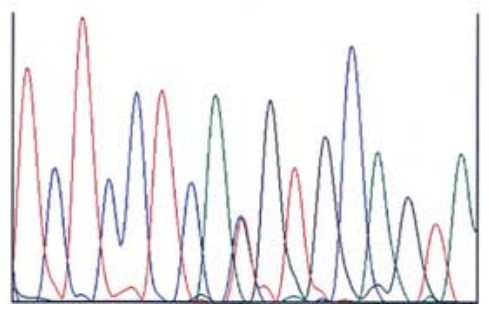

Fig. 2. Sequence analysis of exon 3 of the cationic trypsinogen gene in a control subject and in patient R.D. The schematic diagram of the structure of the human cationic trypsinogen gene (upper panel) illustrates the location of the $\mathrm{C} \rightarrow \mathrm{T}$ mutation (boxed) which results in the replacement of amino acid 116, arginine (CGT), by cysteine (TGT). The lower panel contains the corresponding sequencing electropherograms from a control (upper part) and from the heterozygous proband R.D. (lower part). cence in the absence of etiological factors such as alcohol abuse, hypertriglyceridemia, and hyperparathyroidism [for a review see 23].

The disorder has been shown to be caused by mutations in the cationic trypsinogen gene. Suggested criteria for genetic testing are one or two relatives with pancreatitis, patients with idiopathic chronic pancreatitis before 
Fig. 3. Bbr PI restriction enzyme digestion of PCR-amplified exon 3 products of the cationic trypsinogen gene from the mother Z.D. $(-/-)$, the father M.D. (+/-), the proband R.D. $(+/-)$, the son E.D. (+/-), and the daughter R.D., $\mathrm{Jr}(+/-)$ for detection of the R116C substitution. Exon 3 was amplified from genomic DNA using primer pair CT31 and CT3-2, as shown in the upper panel. Below, the fragment sizes produced by $\mathrm{Bbr}$ PI digest in the absence and in the heteroallelic presence of the $\mathrm{C} \rightarrow \mathrm{T}$ gene mutation are illustrated. The lower panel contains an agarose gel electropherogram of exon 3 amplification products from the heterozygous proband and his immediate relatives after digestion with the restriction enzyme Bbr PI. A nucleic acid molecular size standard (M) was loaded in the left and in the right lanes, and the size of the fragments (in base pairs) is given on the left side. The sizes of the digested PCR products are shown on the right side.

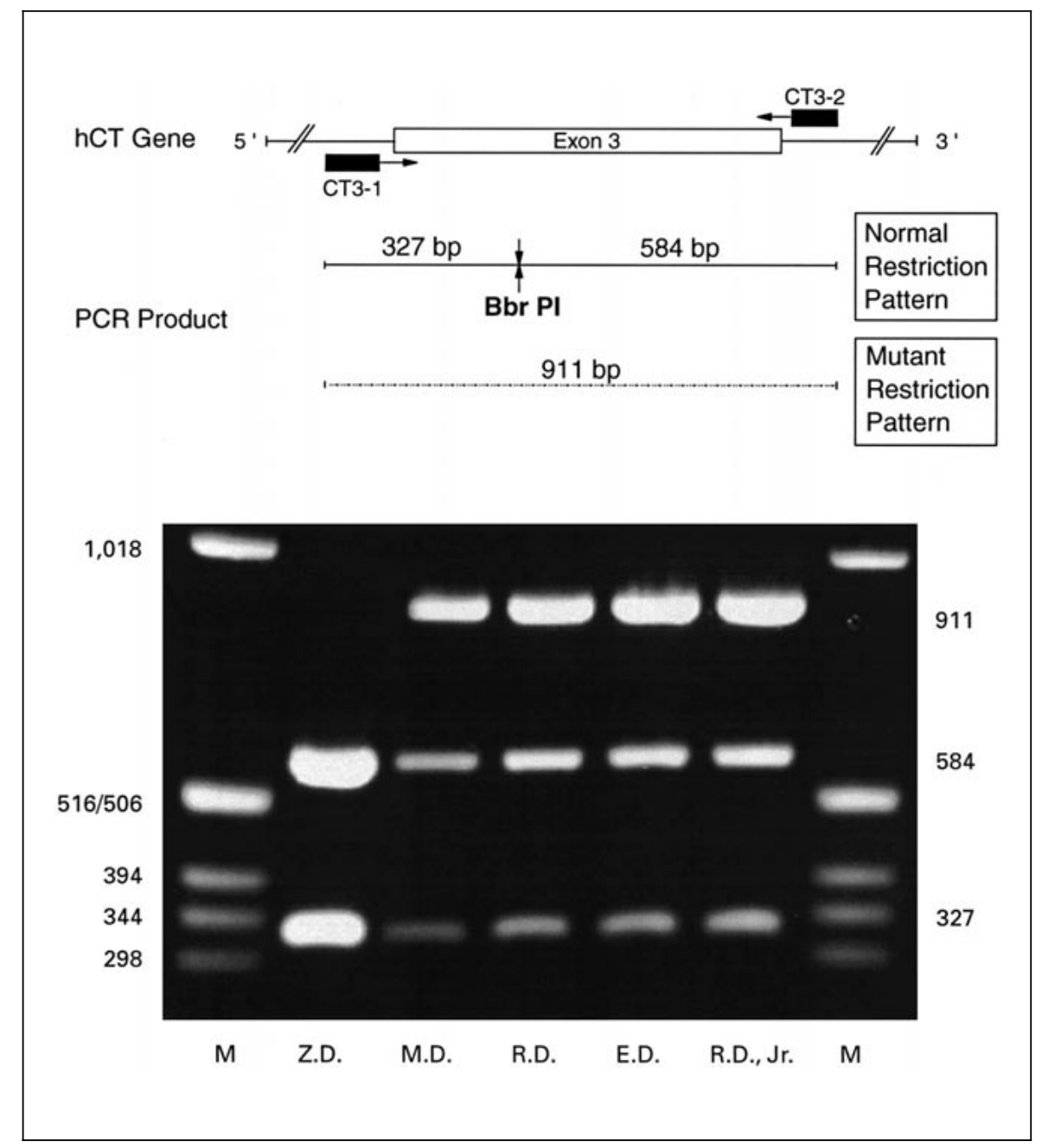

the age of 30 years, and probands with pancreatic carcinoma before the age of 45 years. A facultative criterion is recurrent and unclear abdominal pain during childhood independent of amylase and lipase levels [24].

A negative family history, however, does not exclude the diagnosis of hereditary pancreatitis. Because of the incomplete phenotypic penetrance of approximately $80 \%$, a new index patient has a $20 \%$ probability that his parents are asymptomatic carriers of the disease. In addition, the patients may be not aware of a positive family history, as their relatives can (1) be misdiagnosed, (2) have only mild symptoms, or (3) present with just one clinical feature such as diabetes mellitus or chronic undiagnosed abdominal pain [25].

Thus far, eleven different mutations in exons 1 (TCC deletion at position -28 to -30 with respect to the ATG start codon), 2 (A16V, D22G, K23R, N29I, and P36R), and 3 (E79K, G83E, K92N, R122H, and V123M) of the cationic trypsinogen gene have been described in the literature as the molecular basis of hereditary pancreatitis [9, 11, 19-22]. In addition, three allelic variants (L104P, $\mathrm{R} 116 \mathrm{C}$, and $\mathrm{C} 139 \mathrm{~F}$ ) have been reported to Genbank (accession Nos. AF315309-AF315311).

Trypsinogen is a serine protease proenzyme (zymogen) synthesized by the pancreatic acinar cells. It is converted to trypsin in the duodenum by enterokinase which hydrolyzes the peptide bond between the eight-amino-acid trypsinogen activation peptide and the mature protein. Trypsin in turn activates itself as well as intestinal digestive enzymes by hydrolysis of the respective activation peptides. Because trypsin is such a potent protease, defense mechanisms exist to prevent prolonged action of trypsin if 
prematurely activated within the pancreas. Of these, pancreatic secretory trypsin inhibitor is the most important. By competitive inhibition at the catalytic site, it can deactivate up to $20 \%$ of the trypsin molecules. The remaining trypsin is hydrolyzed by other trypsin molecules or by the trypsinlike enzymes mesotrypsin and molecule $Y$ through proteolytic cleavage of the hinge region between the $\mathrm{N}$ and C-terminal domains at residue R122 (in the trypsinogen nomenclature) which is believed to represent the primary proteolysis site [26-32].

The most common $\mathrm{R} 122 \mathrm{H}$ mutation eliminates this site of hydrolysis and, therefore, renders trypsin resistant to autolysis, resulting in higher concentrations of trypsin, autodigestion of the pancreas, and pancreatitis [1-4, 9]. Both the R122H and the N29I substitution, the second most common cause of hereditary pancreatitis, have also been shown to significantly enhance autoactivation of human cationic trypsinogen in vitro which in turn leads to higher levels of trypsin being generated in pancreatic acinar cells [33]. An alternative hypothesis has been put forward by Whitcomb and coworkers [2, 4]: The conformational change associated with the N29I mutation is proposed to result in the formation of a salt bridge between residues E32 and R122 which in turn prevents the A117L128 side chain from rotating outward, a movement which appears to be necessary to expose the peptide bond between R122 and V123 to other trypsin and trypsinlike molecules for hydrolytic cleavage.

The $\mathrm{R} 116 \mathrm{C}$ amino acid substitution described in this study may have a similar effect on the motion of the semiflexible side chain containing R122. As the mutation is located adjacent to the twelve-residue-connecting side chain A117-L128, it is conceivable that the R116C replacement interferes with the movement of the oligopeptide chain into the hydrolysis-sensitive position, thereby preventing the critical autolysis site at R122 from being attacked. This would result in resistance to trypsin inactivation, enhanced trypsinogen activation, acinar cell autodigestion, and acute pancreatitis.

The R116C substitution occurs at a position not conserved among the human anionic trypsinogen, mesotrypsinogen, and chymotrypsinogen proteins where arginine is replaced by proline [3]. Computer modeling ( $\mathrm{PC} /$ GENE) of cationic trypsinogen with either cysteine or proline at position 116 demonstrated, however, that cysteine, but not proline, significantly decreases the chain flexibility of residues $112-118$ of cationic trypsinogen, as cysteine, in contrast to proline, is a rigid residue [34]. In addition, while proline is an accepted amino acid substitution for arginine, as suggested by the empirical Dayhoff substitutability matrix ( $6 \%$ of the total changes detected for arginine in the sequences of related proteins), cysteine is not ( $0.9 \%$ of the total changes) [35].

In approximately $4-5 \%$ of our idiopathic chronic pancreatitis cases, the disease is caused by a mutation in the cationic trypsinogen gene. In contrast to earlier assumptions, however, the number of autosomal dominant mutations associated with hereditary pancreatitis appears to be unexpectedly large. This mutational heterogeneity of cationic trypsinogen alleles is expected to have practical implications. In our opinion, it is certainly not sufficient to screen patients with chronic pancreatitis only for the two most prevalent N29I and R122H mutations in order to reach satisfactory carrier detection levels. Although most of the other mutated alleles appear to be much rarer, at present the only way to detect all carriers and all possible mutations is to sequence all five exons of the cationic trypsinogen gene. This is easily feasible despite the fact that its sequence is highly homologous to that of other trypsinogen genes within the $\mathrm{T}$ cell receptor beta locus [9]. The cost of this approach will be higher than that of other mutation screening tests, but it has the clear advantage of providing a definitive answer as to whether the patient in question suffers from hereditary pancreatitis or not. This has significant clinical ramifications for the individual and his family with regard to disease course and pancreatic cancer risk.

\section{Acknowledgments}

This study was made possible by the cooperation of the patient and his family. The authors also wish to thank Dr. David C. Whitcomb (University of Pittsburgh) for providing the sequences of the oligonucleotide primer pairs. 


\section{References}

1 Whitcomb DC: Hereditary pancreatitis: New insights into acute and chronic pancreatitis. Gut 1999;45:317-322.

2 Gates LK Jr, Ulrich CD 2nd, Whitcomb DC: Hereditary pancreatitis: Gene defects and their implications. Surg Clin North Am 1999;79: 711-722.

3 O'Reilly DA, Kingsnorth AN: Hereditary pancreatitis and mutations of the cationic trypsinogen gene. Br J Surg 2000;87:708-717.

4 Whitcomb DC: Genetic predisposition to acute and chronic pancreatitis. Med Clin North Am 2000;84:531-547.

5 Lowenfels AB, Maisonneuve P, Whitcomb DC and the International Hereditary Pancreatitis Study Group: Risk factors for cancer in hereditary pancreatitis. Med Clin North Am 2000;84: 565-573.

6 Comfort MW, Steinberg AG: Pedigree of a family with hereditary chronic relapsing pancreatitis. Gastroenterology 1952;21:54-63.

7 Freud E, Barak R, Ziv N, Leiser A, Dinari G, Mor C, Zer M: Familial chronic pancreatitis in identical twins: Case report and review of the literature. Arch Surg 1992;127:1125-1128.

8 Sossenheimer MJ, Aston CE, Preston RA, Gates LK Jr, Ulrich CD, Martin SP, Zhang Y, Gorry MC, Ehrlich GD, Whitcomb DC for the Midwest Multicenter Pancreatic Study Group (MMPSG): Clinical characteristics of hereditary pancreatitis in a large family, based on high-risk haplotype. Am J Gastroenterol 1997; 92:1113-1116.

9 Whitcomb DC, Gorry MC, Preston RA, Furey W, Sossenheimer MJ, Ulrich CD, Martin SP, Gates LK Jr, Amann ST, Toskes PP, Liddle R, McGrath K, Uomo G, Post JC, Ehrlich GD Hereditary pancreatitis is caused by a mutation in the cationic trypsinogen gene. Nat Genet 1996;14:141-145.

10 Teich N, Mössner J, Keim V: Mutations of the cationic trypsinogen in hereditary pancreatitis. Hum Mutat 1998;12:39-43.

11 Ferec C, Raguenes O, Salomon R, Roche C, Bernard JP, Guillot M, Quere I, Faure C, Mercier B, Audrezet MP, Guillausseau PJ, Dupont C, Munnich A, Bignon JD, Le Bodic L: Mutations in the cationic trypsinogen gene and evidence for genetic heterogeneity in hereditary pancreatitis. J Med Genet 1999;36:228-232.

12 Nishimori I, Kamakura M, Fujikawa-Adachi K, Morita M, Onishi S, Yokoyama K, Makino I, Ishida H, Yamamoto M, Watanabe S, Ogawa M: Mutations in exons 2 and 3 of the cationic trypsinogen gene in Japanese families with hereditary pancreatitis. Gut 1999;44:259-263.
13 Creighton JE, Lyall R, Wilson DI, Curtis A, Charnley RM: Mutations of the cationic trypsinogen gene in patients with hereditary pancreatitis. Br J Surg 2000;87:170-175.

14 Whitcomb DC, Preston RA, Aston CE, Sossenheimer MJ, Barua PS, Zhang Y, Wong-Chong A, White GJ, Wood PG, Gates LK Jr, Ulrich C, Martin SP, Post JC, Ehrlich GD: A gene for hereditary pancreatitis maps to chromosome 7q35. Gastroenterology 1996;110:1975-1980.

15 Le Bodic L, Bignon JD, Raguenes O, Mercier B, Georgelin T, Schnee M, Soulard F, Gagne K, Bonneville F, Muller JY, Bachner L, Ferec C: The hereditary pancreatitis gene maps to long arm of chromosome 7. Hum Mol Genet 1996; 5:549-554.

16 Rowen L, Koop BF, Hood L: The complete 685-kilobase DNA sequence of the human beta T cell receptor locus. Science 1996;272:17551762.

17 Emi M, Nakamura Y, Ogawa M, Yamamoto T, Nishide T, Mori T, Matsubara K: Cloning, characterization and nucleotide sequences of two cDNAs encoding human pancreatic trypsinogens. Gene 1986;41:305-310.

18 Tani T, Kawashima I, Mita K, Takiguchi Y: Nucleotide sequence of the human pancreatic trypsinogen III cDNA. Nucleic Acids Res 1990;18:1631.

19 Gorry M, Gabbaizedeh D, Furey W, Gates LK Jr, Preston RA, Aston CE, Zhang Y, Ulrich C, Ehrlich GD, Whitcomb DC: Mutations in the cationic trypsinogen gene are associated with recurrent acute and chronic pancreatitis. Gastroenterology 1997;113:1063-1068.

20 Witt H, Luck W, Becker M: A signal peptide cleavage mutation in the cationic trypsinogen gene is strongly associated with chronic pancreatitis. Gastroenterology 1999;117:7-10.

21 Teich N, Ockenga J, Hoffmeister A, Manns M, Mössner J, Keim V: Chronic pancreatitis associated with an activation peptide mutation that facilitates trypsin activation. Gastroenterology 2000;119:461-465.

22 Chen JM, Piepoli Bis A, Le Bodic L, Ruszniewski P, Robaszkiewicz M, Deprez PH, Raguenes O, Quere I, Andriulli A, Ferec C: Mutational screening of the cationic trypsinogen gene in a large cohort of subjects with idiopathic chronic pancreatitis. Clin Genet 2001;59: 189-193.
23 Mergener K, Baillie J: Chronic pancreatitis. Lancet 1997;350:1379-1385.

24 Keim V, Tannapfel A, Mössner J: Hereditäre Pankreatitis. Dtsch Ärztebl 1998;95:B1936B1940.

25 Creighton J, Lyall R, Wilson DI, Curtis A, Charnley R: Mutations of the cationic trypsinogen gene in patients with chronic pancreatitis. Lancet 1999;354:42-43.

26 Laskowski M Jr, Ikunoshin K: Protein inhibitors of proteinases. Annu Rev Biochem 1980; 49:593-626.

27 Yamamoto T, Nakamura Y, Nishide T, Emi M, Ogawa M, Mori T, Matsubara K: Molecular cloning and nucleotide sequence of human pancreatic secretory trypsin inhibitor (PSTI) cDNA. Biochem Biophys Res Commun 1985; 132:605-612.

28 Rinderknecht H: Activation of pancreatic zymogens: Normal activation, premature intrapancreatic activation, protective mechanisms against inappropriate activation. Dig Dis Sci 1986;31:314-321.

29 Rovery M: Limited proteolyses in pancreatic chymotrypsinogens and trypsinogens. Biochimie 1988:70:1131-1135.

30 Rinderknecht $\mathrm{H}$ : Pancreatic secretory enzymes; in Go VLW, DiMagno EP, Gardner JD, Lebenthal E, Reber HA, Scheele GA (eds): The Pancreas: Biology, Pathobiology, and Disease, ed 2. New York, Raven Press, 1993, pp 219_ 251.

31 Lowe M: The structure and function of pancreatic enzymes; in Johnson I (ed): Physiology of the Gastrointestinal Tract, ed 3. New York, Raven Press, 1994, pp 1531-1542.

32 Hubbard SJ, Eisenmenger F, Thornton JM Modeling studies of the change in conformation required for cleavage of limited proteolytic sites. Protein Sci 1994;3:757-768.

33 Sahin-Tóth M, Tóth M: Gain-of-function mutations associated with hereditary pancreatitis enhance autoactivation of human cationic trypsinogen. Biochem Biophys Res Commun 2000;278:286-289.

34 Karplus PA, Schulz GE: Prediction of chain flexibility in proteins. Naturwissenschaften 1985;72:212-213.

35 Dayhoff MO: Atlas of Protein Sequence and Structure. Washington, National Biomedical Research Foundation, 1978, vol 5, suppl 3, pp 345-358. 